\title{
Self-Starting DC:DC Boost Converter for Low-Power and Low-Voltage Microbial Electric Generators
}

\author{
Nicolas Degrenne, François Buret, Florent Morel, \\ Salah-Eddine Adami, Denis Labrousse \\ Université de Lyon, Ecole Centrale de Lyon, \\ Laboratoire Ampère, UMR 5005 \\ Ecully, France \\ firstname.surname@ec-lyon.fr
}

\begin{abstract}
This paper describes and evaluates an original boost converter able to harvest energy from low-power and lowvoltage power sources. Design and sizing are made according to specifications issued from the stringent characteristics of microbial electric generators such as microbial fuel cells and microbial desalination cells. The harvested power is $10 \mathrm{~mW}$ under input voltage $\mathrm{Vin}=0.3 \mathrm{~V}$ (33mA input current). The design of the converter is adapted from a classical boost topology. It includes a self-oscillating circuit for autonomous operation, and a simple analog maximum power point regulation. Measurements of the conceived discrete realization enable evaluation of the circuit. Best global efficiency of $74 \%$ is achieved under realistic harvesting conditions.
\end{abstract}

\section{INTRODUCTION}

Microbial electric generators (MEGs) are bioelectrochemical systems that use the metabolisms of bacteria to produce electrical energy from organic matter. This energy can be advantageously used to drive various processes including desalination.

Microbial fuel cells (MFCs) are the most common type of MEG. Researches on this subject started in 1911 when M.C. Potter observed electricity production by bacteria E. coli [1]. These results gained increased interest later when Cohen demonstrated a voltage greater than $35 \mathrm{~V}$ from serially connected MFCs. Research amplified 10 years ago when two applications sprouted. The first is to use MFCs as biological sensors [2]. The second is to use MFCs as energy source to produce electricity while consuming organic matter and eventually decontaminating waste-water [3-4]

MFCs are composed of two electrodes (Fig. 1). The anode is in presence of electrogenic bacteria and organic matter. The cathode is in presence of oxygen. When bacteria consume organic matter, complex molecules are broken and electrons and protons are liberated. Electrons migrate to the anode in different ways (direct transfer, electron shuttle, or nanowire) [5]. Protons migrate to the cathode through the electrolyte. At the cathode, electrons, protons and oxygen react to form water.

\author{
Bruno Allard, Abderrahime Zaoui \\ Université de Lyon, INSA de Lyon, \\ Laboratoire Ampère, UMR 5005 \\ Villeurbanne, France \\ firstname.surname@insa-lyon.fr
}

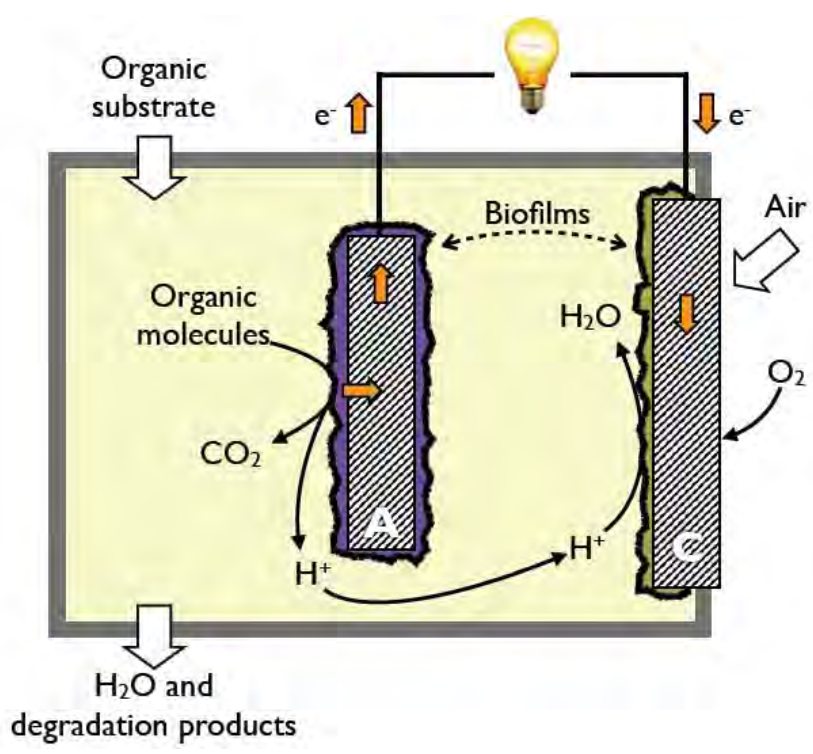

Figure 1. Schematic of a single-chamber MFC

Microbial desalination cells (MDCs) are a combination of MFCs and electrodialysis technologies [6]. The research on this area is at a very early stage. The addition of two membranes between the anode and the cathode of a MFC creates a middle chamber for water desalination between the membranes (Fig. 2). An anion exchange membrane (AEM) is placed on the anode side, and a cation exchange membrane (CEM) is positioned on the cathode side. When the oxidation on the anode creates protons, anions from the middle chamber are transferred into the anode chamber. Identically, cations from the middle chamber are transferred to the cathode chamber when the reduction consumes electrons. These transfers of ions out of the middle chamber enable desalination of the inside water. In addition to desalination, MDCs also enable waste-water treatment and electricity generation just like MFCs. 


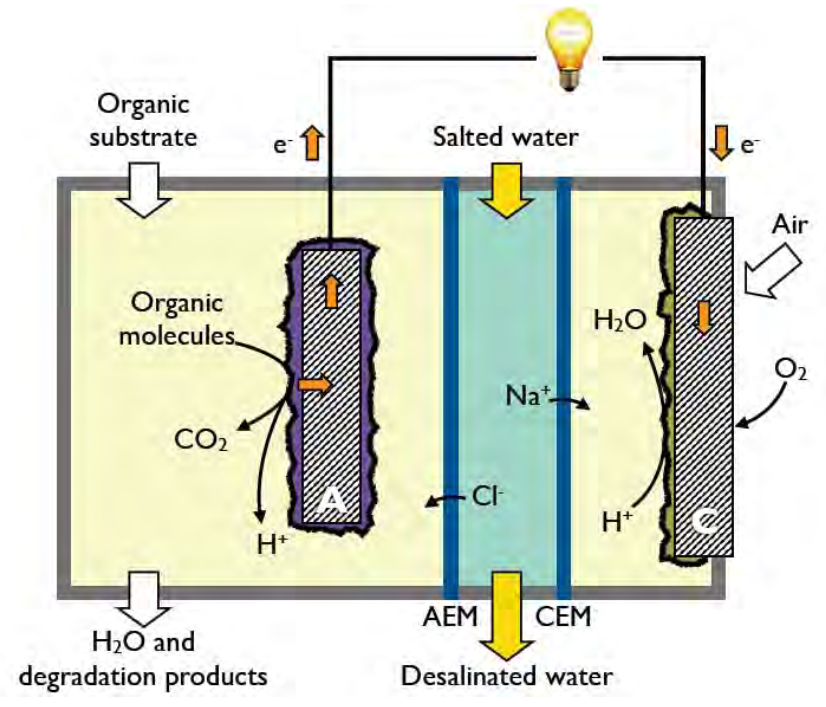

Figure 2. Schematic of a MDC

A similarity between different kinds of MEGs is that they provide a very small amount of power (presently about $1 \mathrm{~mW}$ for a 1-liter single-chamber MFC) under low-voltage (0.3V). Internal presence and nature of substrate and bacteria is inconstant and uncontrollable and has a strong influence on cells electrical characteristics [7]. In the case of MDCs, the salt concentration of the middle membrane has a high influence on the cell internal resistance. These inconstancies cause inevitable dispersions of electrical characteristics (maximum power is obtained under different current conditions) and one consequence is that it is inefficient to associate many cells in series [8]. Therefore, we must rely on low-voltage power conversion structures to valorize the electrical energy produced from MEGs.

Low-power and low-voltage converters require specific design attention. Kimball, in [9], emphasizes start-up and efficiency issues. Most silicon components do not switch at gate voltages below $0.5 \mathrm{~V}$. Once in operation, the output voltage of the step-up converter can be sufficiently high to supply the circuit control. If the output voltage is initially low, specific start-up topologies need to be added like in DC:DC converters compared Table I.

A first option is to realize the start-up circuit independently from the main DC:DC converter. The advantage is to allow the use of a classical high-efficiency main DC:DC converter. In [10], [11] and [12], the boost topology was respectively implemented with a charge-pump, a mechanical, and a transformer-based start-up.

A second option is to merge the start-up and the main circuit in order to decrease the number of components and thus the cost and the reliability. Respectively boost and flyback architectures were presented in [13] and [14]. These two structures are close to the converter presented in this paper.

A third option is to design new architectures especially built for low-voltage and low-power. The architecture presented in [15] is a transformer-based oscillating structure connected with a voltage-doubler circuit. It transfers energy both directly and indirectly. This topology has gained interest recently in energy harvesting applications [16]-[17].

The present paper analyzes a step-up converter topology customized for autonomous operation and sized for harvesting energy from MEGs. It is a modified boost converter which includes self-starting and self-oscillating command. These are based on the association of a transformer which secondary windings control a switch connected in series with the primary windings. This association ensures a positive feedback and sustained oscillations. In order to initiate operation, a normally-ON JFET is used as a switch.

The present paper intends to unveil this original harvesting converter. First, a description of MEGs is given. Specifications for the converters are deduced. Then, the circuit is extensively described and operations principles are detailed. Next, simulations and measurements results are given and discussed.

TABLE I. HARVESTING DC:DC CONVERTERS COMPARISON

\begin{tabular}{|c|c|c|c|c|c|}
\hline \multirow[t]{2}{*}{ Circuit } & \multicolumn{5}{|c|}{ Description } \\
\hline & Start-up voltage & Power range & Vout & MPPT & Peak efficiency \\
\hline $\begin{array}{l}\text { Linear technologies } \\
\text { LTC310 (1:20) [16] }\end{array}$ & $100 \mathrm{mV}$ & $100 \mu \mathrm{W}$ to $100 \mathrm{~mW}$ & $2.35 \mathrm{~V}$ to $5 \mathrm{~V}$ & no & 0.6 \\
\hline $\begin{array}{c}\text { Enocean } \\
\text { ECT310 [18] }\end{array}$ & $20 \mathrm{mV}$ & $100 \mu \mathrm{W}$ to $100 \mathrm{~mW}$ & $3 \mathrm{~V}$ to $5 \mathrm{~V}$ & no & 0.3 \\
\hline $\begin{array}{c}\text { Seiko } \\
\text { S-882Z [19] }\end{array}$ & $300 \mathrm{mV}$ & ? to $150 \mu \mathrm{W}$ & $1.8 \mathrm{~V}$ to $2.4 \mathrm{~V}$ & no & 0.2 \\
\hline Markus [14] & $70 \mathrm{mV}$ & $200 \mu$ to $16 \mathrm{~mW}$ & $2 \mathrm{~V}$ to $5 \mathrm{~V}$ & no & 0.7 \\
\hline Qiu [20] & $500 \mathrm{mV}$ & $5 \mu \mathrm{W}$ to $10 \mathrm{~mW}$ & $0 \mathrm{~V}$ to $5 \mathrm{~V}$ & yes & 0.7 \\
\hline Ramadass [11] & $35 \mathrm{mV}$ & $10 \mu \mathrm{W}$ to ? & $1.8 \mathrm{~V}$ & yes & 0.58 \\
\hline
\end{tabular}




\section{MICROBIAL ELECTRIC GENERATORS SPECIFICATIONS}

\section{A. Construction of a single-chamber microbial fuel cell}

Because MEGs are derived from MFCs and because their electrical specifications are also very similar to the ones of MFCs, the following study is based on MFCs only. One batch reactor was designed to harvest energy from wastewater. In this purpose, a single-chamber MFC structure was preferred (Fig. 3). The main advantages compared with the dual counterpart are the higher power density, the decreased risks of fouling, and the autonomous aeration of the cathode.

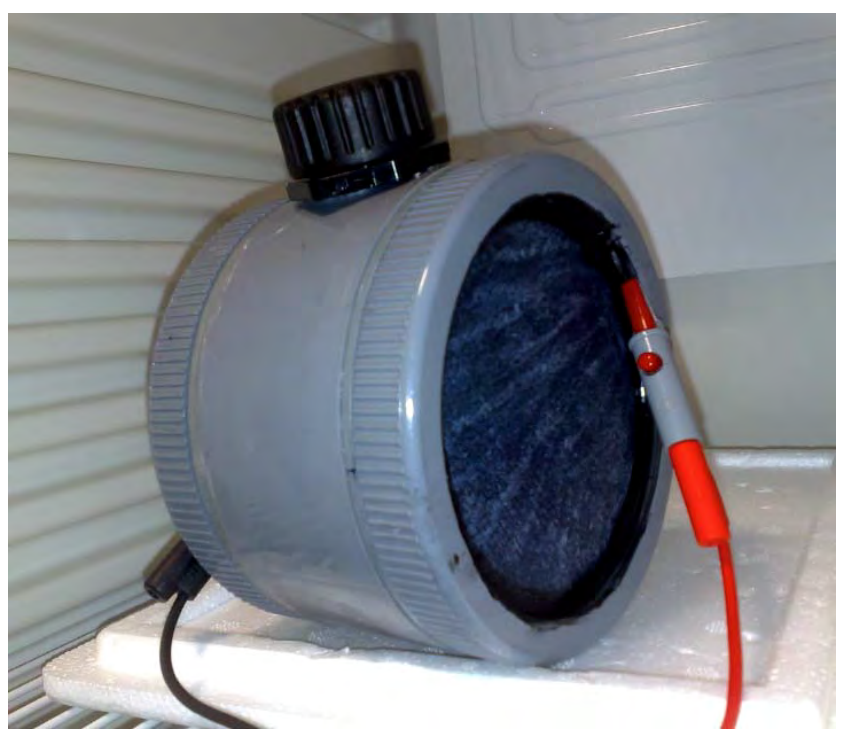

Figure 3. Photograph of the constructed MFC

The main originality of this structure relies on the cathode (usually named air-cathode) which is directly in contact with air on the external side of the reactor. This cathode (Fig. 4) is composed of a frame in carbon cloth on which 4 PTFE layers are coated on the external surface. These layers ensure the water-proofing while enabling oxygen diffusion. On the internal side, a nafion membrane is coated in order to limit the diffusion of oxygen to the anode while permitting the ions to access the cathode. This membrane is supplemented with platinum $\left(0.1 \mathrm{~g} . \mathrm{cm}^{-2}\right)$ to serve as a catalyst. This structure was conceived manually, using directives from Penn State University [21].

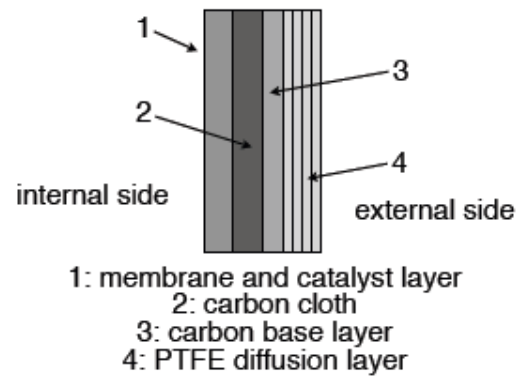

Figure 4. Air-cathode side view
The anode is a graphite fiber brush with titanium base wire to ensure a large specific area (Gordon Brush Inc.). The reactor was conceived standard evacuation pipes in PVC (Nicoll) in order to lower the cost and enable easy reproducibility of the design.

\section{B. Electrical characteristics of a single microbial fuel cell}

Polarization and power density curves of MEGs offer precious information to design the harvesting power electronic module. A polarization curve (Fig. 5) was acquired for the MFC described above. The MFC was previously fed with $0,1 \mathrm{~g}$ of acetate and the curve was acquired under ambient temperature $\approx 25^{\circ} \mathrm{C}$. The load resistance was varied from open-circuit to short circuit using a resistor box. Voltages were measured for each resistance value after a stabilization time of $5 \mathrm{~min}$.

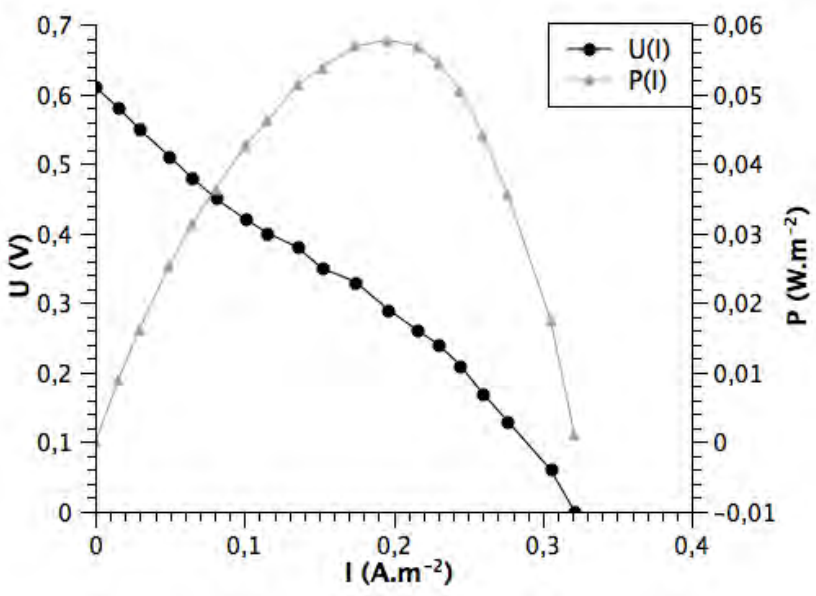

Figure 5. Polarization and power density curves of the constructed MFC

The normalized curves indicates that open-circuit voltage is $\approx 0.6 \mathrm{~V}$, short-circuit current $\approx 0.32 \mathrm{~A} . \mathrm{m}^{-2}$ and maximum power $\approx 58 \mathrm{~mW} \cdot \mathrm{m}^{-2}$ obtained for a maximum power point $(\mathrm{MPP})$ voltage $\approx 0.29 \mathrm{~V}$. For the $\mathrm{MFC}$ we consider, the maximum power was $540 \mu \mathrm{W}$ obtained for a current of $1.84 \mathrm{~mA}$, at a voltage of $0.29 \mathrm{~V}$ and with a $160 \Omega$ external load resistor.

It is now common to find in literature power densities up to few W.m $\mathrm{m}^{-2}$ [22]. These results are usually obtained for small scale reactors which use platinum in higher concentrations. Those MFCs are difficultly scalable and their price is inherently high.

\section{Basic microbial fuel cell model}

The output voltage of fuel cells is usually described as an open-circuit voltage to which we subtract 3 different kinds of current-dependant voltage losses: activation losses, resistive losses, and diffusion losses (also called concentration losses). These losses are dependant on temperature and on fuel concentration. 


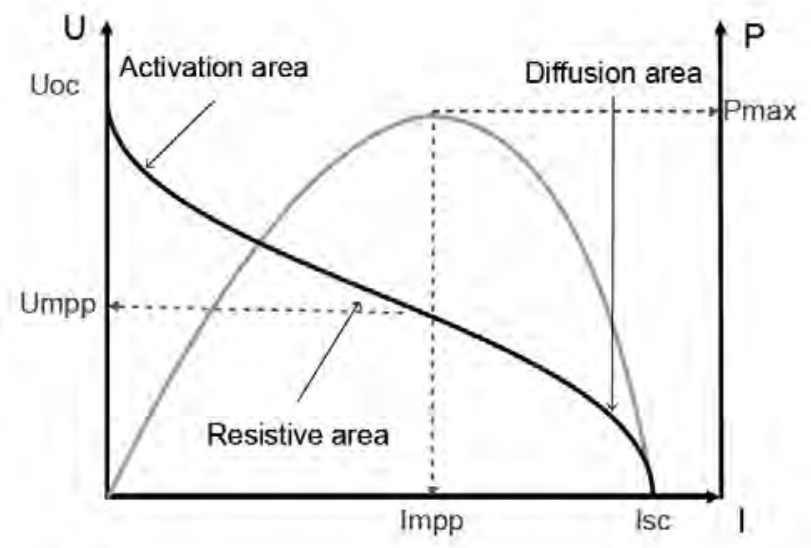

Figure 6. Theoretical polarization and power density curves for a typical fuel cell

A realistic model would consider these 3 voltage losses and compute them for determined experimental conditions of temperature and fuel concentrations. In this paper, the model was largely approximated and only considers equivalent resistive losses. MEGs are therefore assumed to all correspond to the electrical circuit (Fig. 7), with an open circuit voltage of $0.6 \mathrm{~V}$ and an internal serial resistance $\approx 160 \Omega$.

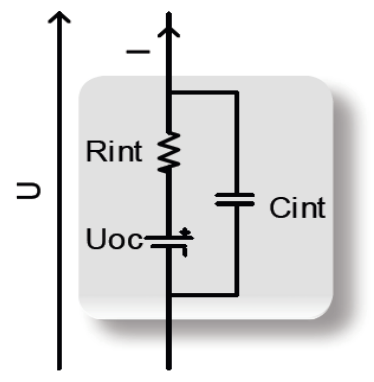

Figure 7. Simplified model of a MFC

\section{Association of microbial fuel cells}

MFCs were tested under different fuel conditions, and it was found that the internal equivalent resistance (Rint) increases and open-circuit voltage is almost constant when fuel concentration decreases. In this case, the maximum power point (MPP) voltage is identical for two reactors while the MPP current is different (Fig. 8). For this reason, parallel association is preferred. The issue with parallel association is that the voltages are low $(\approx 0.3 \mathrm{~V})$. The current can be increased by multiplying the number of connected cells. Since a single laboratory MFC like described above outputs $1.84 \mathrm{~mA}$, we chose to design a converter for a current of $33 \mathrm{~mA}$, corresponding to $10 \mathrm{~mW}$ (under $0.3 \mathrm{~V}$ ) and to $18 \mathrm{lab}$ cells in parallel.

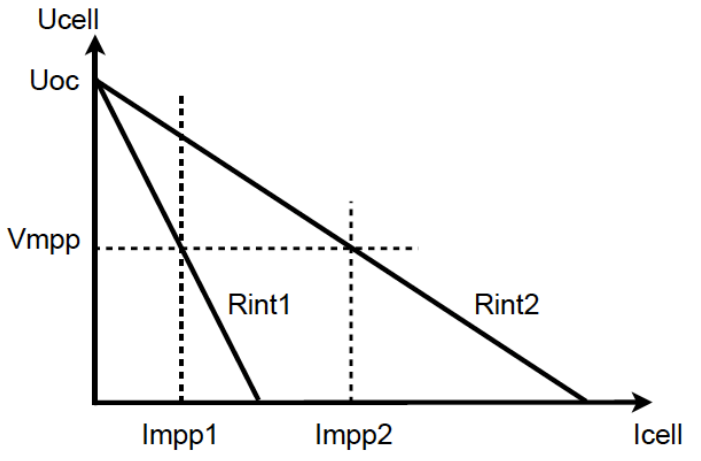

Figure 8. Ppolarization curves for parallel associations

\section{E. DC:DC converter specifications}

The converter ideally includes maximum power point tracking (MPPT) function to harvest the maximum available power from the source regardless of its internal resistance. A simple way to ensure this function is to regulate the input voltage to a value Vmpp like introduced above. The output voltage should not be regulated precisely, but must be above $1 \mathrm{~V}$ in order to enable a second step-up stage realized in conventional CMOS technology.

TABLE II. SPECIFICATIONS OF THE DC:DC CONVERTER

\begin{tabular}{|c|c|c|c|c|c|}
\hline & \multicolumn{5}{|c|}{ Specifications } \\
\cline { 2 - 6 } & Name & Unit & Min & Typical & Max \\
\hline $\begin{array}{c}\text { Input open-circuit } \\
\text { voltage }\end{array}$ & Vin0 & $\mathrm{V}$ & 0.5 & 0.6 & 0.7 \\
\hline $\begin{array}{c}\text { Input source serial } \\
\text { resistance }\end{array}$ & Rint & $\Omega$ & 3 & 9 & 45 \\
\hline $\begin{array}{c}\text { Input regulated } \\
\text { voltage }\end{array}$ & Vin & $\mathrm{V}$ & 0.2 & 0.3 & 0.4 \\
\hline $\begin{array}{c}\text { Global efficiency } \\
\text { Output voltage }\end{array}$ & Vout & $\mathrm{V}$ & $1 \mathrm{~V}$ & & \\
\hline
\end{tabular}

\section{CIRCUIT PRESENTATION}

\section{A. Architecture}

The converter presented Fig. 9 is based on a conventional boost converter like proposed in [14]. The main circuit inductor $\mathrm{L}_{1}$ is coupled to $\mathrm{L}_{2}$ to feed start-up, self oscillating, and regulation circuits.

\section{B. Sizing}

The circuit was designed using Orcad software with SPICE models for each part at the exception of the transformer which model is unavailable and which was replaced by an ideal linear transformer $(\mathrm{L} 1=326.7 \mu \mathrm{H}$, $\mathrm{L} 2=8167 \mu \mathrm{H}$, coupling $\mathrm{K}=0.999$ ) with serial resistances $\mathrm{R}_{\mathrm{L} 1}=34 \mathrm{~m} \Omega$ and $\mathrm{R}_{\mathrm{L} 2}=170 \mathrm{~m} \Omega$. Different component values and references were simulated in order to identify an effective configuration which permits proper operation at high efficiency (Table III). 


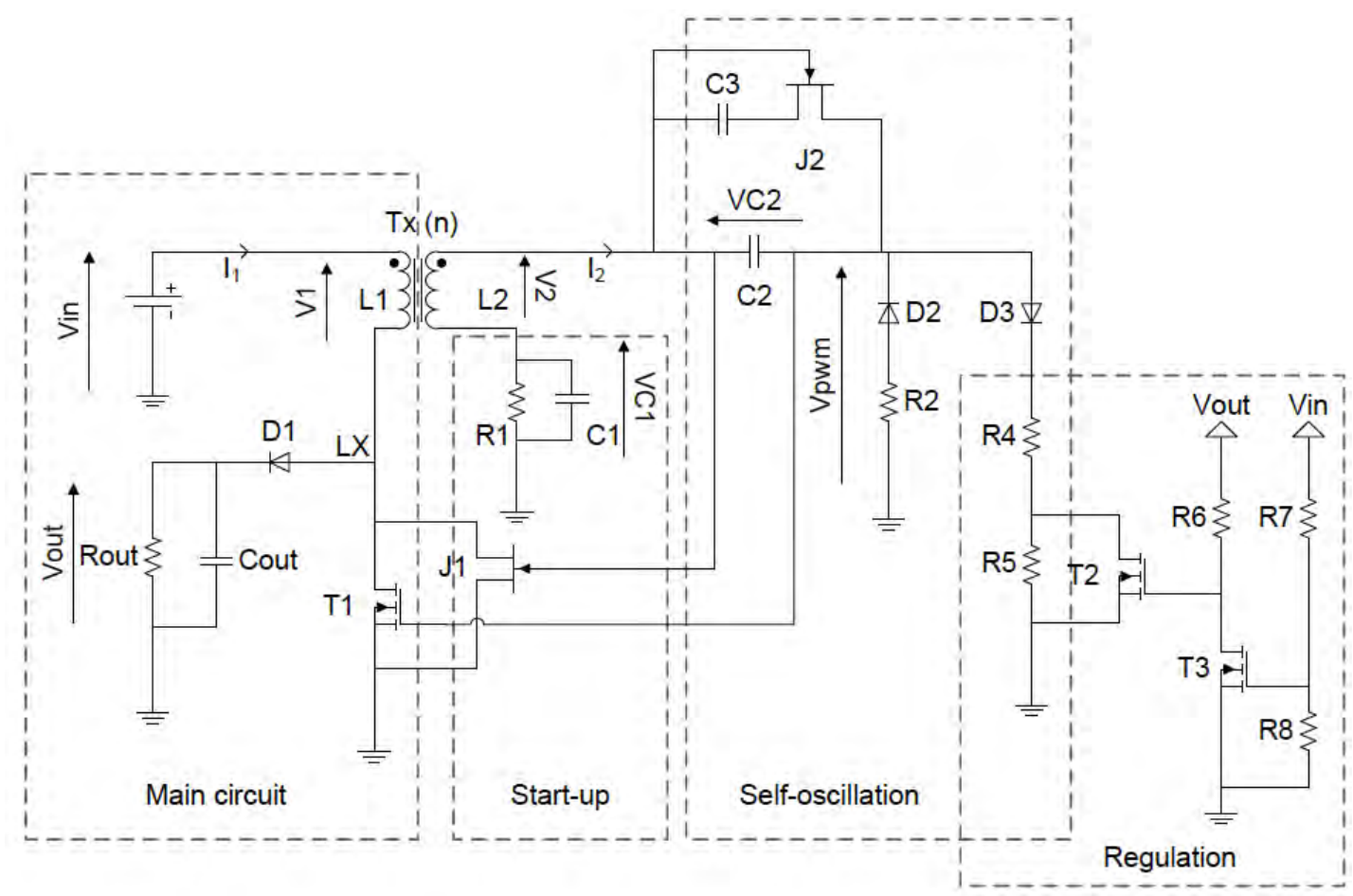

Figure 9. Schematic of the converter powered by an ideal voltage source and loaded by a resistor

TABLE III. COMPONENT VALUES AND REFERENCES

\begin{tabular}{|c|c|c|c|}
\hline \multirow{2}{*}{ Part } & \multicolumn{3}{|c|}{ Description } \\
\hline & Type & Company & Reference \\
\hline Vin & Voltage source & & $0.3 \mathrm{~V}$ \\
\hline $\mathrm{Tx}$ & Transformer (1:5) & Wurth Elektronik & WE749197301 \\
\hline $\mathrm{T} 1$ & Transistor NMOS & Diode Inc & DMG6968 \\
\hline $\mathrm{T} 2, \mathrm{~T} 3$ & Transistor & $\begin{array}{c}\text { Advanced Linear } \\
\text { Devices }\end{array}$ & ALD110802 \\
\hline J1, J2 & Transistor JFET & NXP & JBF862 \\
\hline D1 & Diode & Diode Inc & BAT54 \\
\hline D2, D3 & Diode & $\begin{array}{c}\text { Avago } \\
\text { technologies }\end{array}$ & HSMS285X \\
\hline $\begin{array}{l}\text { R1, } \\
\text { Rout }\end{array}$ & Resistor & & $1 \mathrm{k} \Omega$ \\
\hline R2 & Resistor & & $50 \Omega$ \\
\hline R4 & Resistor & & $20 \mathrm{k} \Omega$ \\
\hline R5 & Resistor & & $500 \mathrm{k} \Omega$ \\
\hline R6 & Resistor & & $2 \mathrm{M} \Omega$ \\
\hline R7 & Resistor & & $100 \mathrm{k} \Omega$ \\
\hline R8 & Resistor & & $200 \mathrm{k} \Omega$ \\
\hline $\begin{array}{l}\text { C1, } \\
\text { Cout }\end{array}$ & Capacitor & & $8 \mu \mathrm{F}$ \\
\hline C2 & Capacitor & & $300 \mathrm{pF}$ \\
\hline C3 & Capacitor & & $3 n F$ \\
\hline
\end{tabular}

\section{CIRCUIT OPERATION}

\section{A. Main boost}

The main circuit is an asynchronous boost converter operating at the boundary of the continuous and discontinuous mode (critical conduction mode). Ideal step-up ratio is given by (1), D being the duty cycle.

$$
\frac{\text { Vout }}{\text { Vin }}=\frac{1}{1-D} \text {. }
$$

\section{B. Self-oscillation}

The boost main switch $T_{1}$ is controlled by a pulse-width modulated signal $\mathrm{V}_{\mathrm{PWM}}$. During steady-state, the primary winding of the transformer is either subject to voltage $\mathrm{V}_{1}=\mathrm{V}_{\text {IN }}$ during the ON-state of $\mathrm{T}_{1}$ (Tup), either to $\mathrm{V}_{1}=\mathrm{V}_{\mathrm{IN}^{-}}$ $\mathrm{V}_{\text {OUT }}$ during the OFF-state of $\mathrm{T}_{1}$ (Tdown). If $\mathrm{L}_{1}$ and $\mathrm{L}_{2}$ are considered ideally coupled, V2 $=\mathrm{n} * \mathrm{~V} 1$.

During Tup, V2 $=\mathrm{n}^{*} \mathrm{Vin}$ and Vpwm is positive (we assume VC2 $=0$ ). Diode D3 is ON and the capacitor C2 charges (VC2 increases) in the equivalent serial resistance (to D3) with defined time constant. The voltage Vpwm decreases and when it reaches the threshold voltage Vth of T1, it turns OFF.

During Tdown, diode D2 is ON. The capacitor C2 discharges (VC2 decreases) through R2. Tdown lasts until the current through the diode D1 decreases to zero and cancels. I1 gets negative (through the body-diode of T1), 
lowers the LX node voltage and inverts voltage V1 at the primary winding of the transformer. When D3 is ON again (Tup), the initial PWM voltage (Vpwmmax) will be higher than Vth because VC2 decreased during Tdown. The discontinuities of Vpwm are theoretically equal to the discontinuities of V2 (= $n^{*}$ Vout).

The experimental measures (Fig. 11) were acquired such that Vin $=0.3 \mathrm{~V}$ and Vout $=2.7 \mathrm{~V}$. The amplitude of V2 is about $17.6 \mathrm{~V}$ which is higher than $\mathrm{n}^{*}$ Vout $=5 * 2.7$. The reason can be partially found in the presence of a threshold voltage Vd1 for diode D1 which imposes an amplitude equal to $\mathrm{n}^{*}($ Vout+Vd1). The measured amplitude of Vpwm is close to $3 \mathrm{~V}$ which is a less than the $17.6 \mathrm{~V}$ expected. The reason is that the equivalent parasitic capacitance Cpwm (composed of the parasitic capacitances in the interconnections and in T1, D2, D3 and J2) seen at the gate of $\mathrm{T} 1$ is high compared to C2. The currents required to charge Cpwm at each commutation cause apparent discontinuities of VC2 and attenuation of the amplitude of Vpwm.

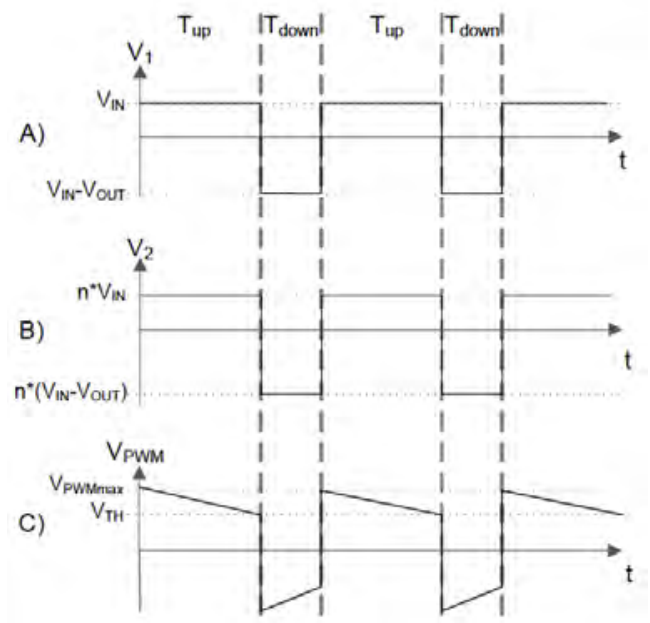

Figure 10. Theoretical shapes of the converter

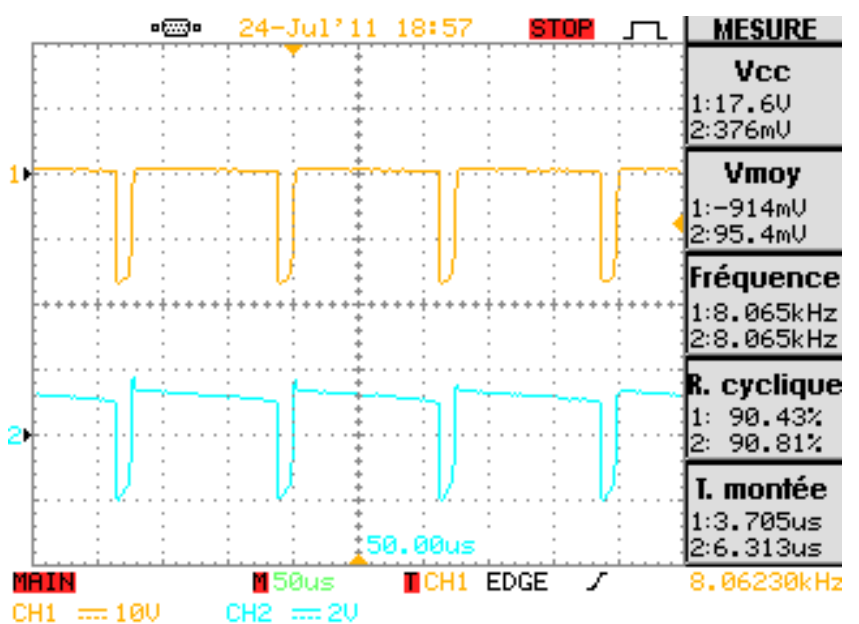

Figure 11. Experimental shapes of V2 (above) and of Vpwm (below)

\section{Regulation}

The regulation loop controls the input voltage $V_{\text {IN }}$. It modifies the equivalent resistance (serially connected to $\mathrm{D}_{3}$ ) that sets Tup and the switching frequency ( $\mathrm{f} \approx 8 \mathrm{kHz}$ for Rint $=9 \Omega$ ). Transistor $T_{3}$ is a specific ultra-low voltage NMOS transistor. $T_{3}$ drives transistor $T_{2}$ through a logic-inverter structure $\left(R_{6}\right.$ and $\left.T_{3}\right)$ which is supplied by the output voltage of the converter. Resistors $R_{4}$ and $R_{5}$ are necessary to adapt minimum and maximum values of the equivalent serial resistance.

\section{Start-up}

JFET $\mathrm{J}_{1}$ is connected in parallel with NMOS $T_{1}$ and enables autonomous start-up. When a positive voltage $V_{\text {IN }}$ is applied at the input, the current $\mathrm{I}_{1}$ through the primary winding and through the normally-ON JFET $\mathrm{T}_{1}$ increases. The voltage $V_{2}=n^{*} V_{1} \quad\left(n=n_{2} / n_{1}=5\right.$ turn-ratio $)$ at the secondary winding is positive. Since the gate of $T_{1}$ is biased positively (initially $\mathrm{V}_{\mathrm{C} 1}=0$ ), the internal diode of $\mathrm{T}_{1}$ conducts and $V_{C 1}$ gets negative. When the current $I_{1}$ is high enough, $V_{1}$ decreases ( $R * L$ time constant), and $V_{2}$ decreases. The gate voltage of $\mathrm{J}_{1}$ therefore decreases, and its $\mathrm{ON}-$ resistance increases. $\mathrm{J}_{1}$ is driven slightly towards the offstate.

When $J_{1}$ is OFF, the current $I_{1}$ decreases through $D_{1} \cdot V_{1}$ and $V_{2}$ get negative. When $I_{1}$ gets negative, voltage $V_{1}$ increases, $V_{2}$ increases and $\mathrm{T}_{1}$ switches $\mathrm{ON}$ again. Oscillations amplify and the output capacitor $\mathrm{C}_{3}$ is charged, amplifying the current slopes. At a certain point, the amplitude of oscillations is high enough and $\mathrm{T}_{1}$ switches $\mathrm{ON}$ and OFF synchronously with $\mathrm{J}_{1}$. When the voltage across $\mathrm{C}_{1}$ is negative enough, $\mathrm{J}_{1}$ stops switching.

\section{EXPERIMENTATION RESULTS}

The circuit was realized on a printed circuit board (PCB) using discrete components (Fig. 12). Resistors R2, R4, R5 and R7 were replaced by potentiometer to enable manual tuning of the regulation.

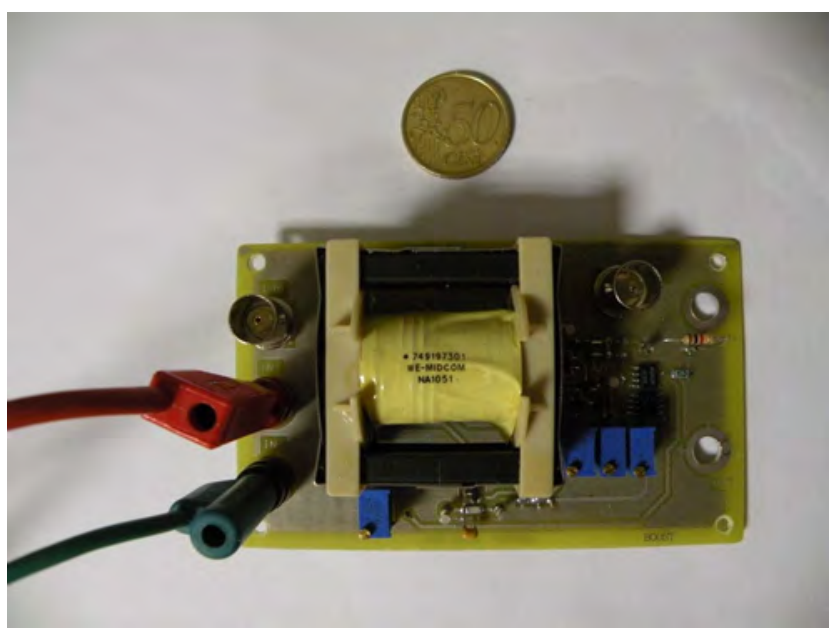

Figure 12. photograph of the printed circuit board of the circuit 
The most critical part of the circuit is the transformer which consumes almost half of the PCB area, and which accounts for most of the circuit total cost. This transformer was chosen for its large primary inductance, low serial resistance, and high turn-ratio. More compact transformers can be used, but their higher serial resistances cause additional conduction losses and their lower primary inductance impose a higher switching frequency leading to increased switching losses.

The circuit was tested upon varied source characteristics, corresponding to MFCs connected in parallel fed under different substrate concentration. The experimental setup (Fig. 13) includes an ideal $0.6 \mathrm{~V}$ voltage source serially connected to a variable resistor Rint (representing the equivalent internal resistance of a MFC). An input capacitor Cin $=1 \mathrm{mF}$ is added in parallel in order to filter the input of the converter. At the output, the load is composed by a resistor parallely connected to an output filter capacitor Cout $=8 \mu \mathrm{F}$.

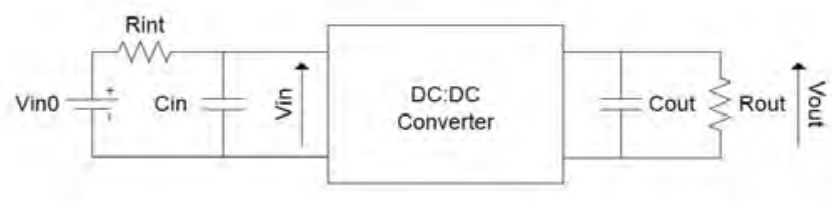

Figure 13. Description of the test methodology

The values of the potentiometer were set in a reproducible way. R4 was set to its minimum value $(0 \Omega)$, R5 to its maximum value $(1 \mathrm{M} \Omega)$. R7 was first set to its minimum value $(0 \Omega)$ and $\mathrm{R} 2$ was set to have an input voltage Vin $=0.25 \mathrm{~V}$ (under nominal Rint $=9 \Omega$ ). R7 was then readjusted to have Vin $=0.3 \mathrm{~V}$.

The converter shows simulated global efficiency of $80.6 \%$. Loss analysis is identical to the boost standard circuits it is derived from, except for additional switching losses due to the self-oscillating circuits. Low switching frequency enables decrease of switching losses at the expense of a large transformer magnetization inductance. Most losses are therefore located in diode D1 and can be decreased with the addition of a parallel MOS transistor (at the cost of circuit complexity). The transformer used is chosen for its very low serial resistance and ensures low conductive losses at the expense of size.

Fig. 14 shows how global efficiency is impacted by the input serial resistance Rint. The discrete realization of the circuit has a lower efficiency than what was expected from simulation, especially for low values of Rint. These differences can be attributed to: (1) improper tuning of the regulation through the choice of potentiometer values, (2) additional losses in the interconnections, (3) large switching loss in the self-oscillation circuit due to high voltage levels, and (4) additional parasitic elements not considered in the model of the transformer (e.g. losses in the magnetic materials and losses due to the parasitic capacitances).
The efficiency of the converter under nominal conditions was measured to be $74 \%$.

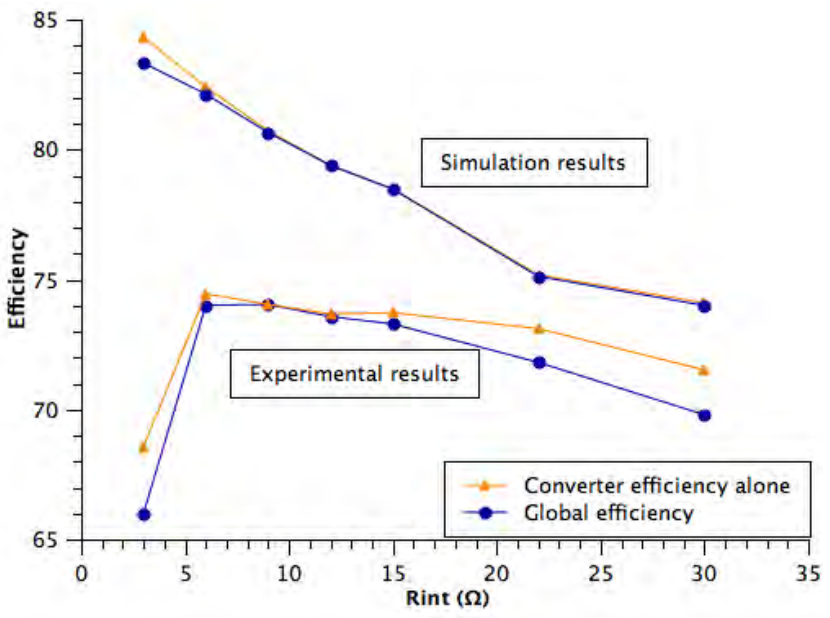

Figure 14. Simulation and experimental efficiency

\section{DisCUSSIONS}

In this section, the proposed converter properties are discussed in term of step-up ability, control and cost.

\section{A. Step-up}

Boost efficiency theoretically decreases when the step-up ratio is high (duty cycle $\mathrm{D}>0.9$ ). It is not verified with the described converter, because of the low switching frequency. The proposed converter steps-up by a ratio over 10 in adequate loading conditions.

\section{B. Control}

The converter includes a regulation loop which is designed to regulate the input voltage (enabling therefore the implementation of MPPT function). The difference between converter efficiency and global efficiency (Fig. 14) corresponds to the losses caused by improper MPPT regulation. The non-effectiveness of the regulation is visible on the experimental results in case of large variations of Rint, but still accounts for less than 3\% efficiency loss. Future works will have to focus on improving MPPT regulation.

\section{Cost}

The circuit is area consuming because of the large inductive elements it requires for operation. Integration of active parts would decrease switching losses, enable higher frequency operation, and decrease constraints on inductive components. Assuming a switching loss reduction of a factor 100 , the primary inductance of the transformer could be sized to equal few micro-henries, which permits the use of compact transformer, but still forbids the thought of a fully integrated circuit.

\section{CONCLUSION}

The paper presents a DC:DC boost converter specifically designed for MEGs. Its self-starting and self-oscillating circuits enable autonomous operation at input voltages of 
$0.3 \mathrm{~V}$. Its high step-up ratio enables outputs voltages above $2 \mathrm{~V}$ depending on loading conditions. The MPPT regulation helps the converter harvest maximum energy from MEGs under variable fuel concentration. The maximum global efficiency achieved experimentally under nominal condition is $74 \%$.

\section{PERSPECTIVES}

One of the next challenges is to modify the circuit so that it can be integrated. In order to foresee a full integration (active and passives), the structure probably has to be largely modified. We propose to separate the main boost circuit from the start-up circuit. The boost converter, if switching at high frequency (in the mega-hertz range) would permit the integration of its inductor. The start-up is necessary, but can be done separately, and differently.

\section{ACKNOWLEDGMENTS}

This work was supported by the MiCoNet 2 grant (ANR 2010 BLAN 0909 01) from the French National Agency for Research.

N. Degrenne thanks Marcelino Seif from Lebanese University for his work in microbial fuel cell modeling.

\section{REFERENCES}

[1] M.C. Potter, "Electrical effects accompanying the decomposition of organic compounds," Royal Society of London. Series B, containing papers of a biological character, vol. 84, 1911, pp. 260-276.

[2] I.S. Chang, J.K. Jang, G.C. Gil, M. Kim, H.J. Kim, B.W. Cho, and B.H. Kim, "Continuous determination of biochemical oxygen demand using microbial fuel cell type biosensor," Biosensors and Bioelectronics, vol. 19, Jan. 2004, pp. 607-613.

[3] S.T. Oh, J.R. Kim, G.C. Premier, T.H. Lee, C. Kim, and W.T. Sloan, "Sustainable wastewater treatment: How might microbial fuel cells contribute," Biotechnology advances, Aug. 2010.

[4] Z. Du, H. Li, and T. Gu, "A state of the art review on microbial fuel cells: A promising technology for wastewater treatment and bioenergy," Biotechnology advances, vol. 25, 2007, pp. 464-82.

[5] D.R. Lovley, "The microbe electric: conversion of organic matter to electricity," Current opinion in biotechnology, vol. 19, 2008, pp. 56471.

[6] X. Cao, X. Huang, P. Liang, K. Xiao, Y. Zhou, X. Zhang, and B.E. Logan, "A new method for water desalination using microbial desalination cells," Environmental science \& technology, vol. 43, Sep. 2009, pp. 7148-52.
[7] E. Martin, O. Savadogo, S.R. Guiot, and B. Tartakovsky, "The influence of operational conditions on the performance of a microbial fuel cell seeded with mesophilic anaerobic sludge," Biochemical Engineering Journal, vol. 51, Sep. 2010, pp. 132-139.

[8] S.E. Oh and B.E. Logan, "Voltage reversal during microbial fuel cell stack operation," Journal of Power Sources, vol. 167, 2007, p. 11-17.

[9] J.W. Kimball, T.L. Flowers, S. Member, and P.L. Chapman, "Lowinput-voltage , low-power boost converter design issues," Power Electronics Letters, vol. 2, 2004, pp. 96-99.

[10] P.-hung Chen, K. Ishida, X. Zhang, Y. Okuma, Y. Ryu, M Takamiya, and T. Sakurai, " $0.18-\mathrm{V}$ input charge pump with forward body biasing in startup circuit using 65nm CMOS," IEEE Custom Integrated Circuits Conference, 2010, pp. 1-4.

[11] Y.K. Ramadass and A.P. Chandrakasan, "A batteryless thermoelectric energy-harvesting interface circuit with $35 \mathrm{mV}$ startup voltage,” IEEE Journal of Solid-State Circuits, 2010, p. 333-341.

[12] J.M. Damaschke, "Design of a low-input-voltage converter for thermoelectric generator," IEEE Transactions on Industry Applications, vol. 33, 1997, pp. 1203-1207.

[13] S. Ben-Yaakov and I. Fridman, "SPICE compatible model of selfoscillating converter," 23rd IEEE Convention of Electrical and Electronics Engineers in Israel, 2004, pp. 342-345.

[14] M. Pollak, L. Mateu, and P. Spies, "Step-up DC-DC-Converter with coupled inductors for low input voltages," Fraunhofer IIS, 2008.

[15] D. Grgić, T. Ungan, M. Kostić, and L.M. Reindl, "Ultra-low input voltage DC-DC converter for micro energy harvesting," PowerMeMs, 2009, pp. 265-268.

[16] Linear Technology, "Ultralow Voltage Step-Up Converter and Power Manager,” LTC3108 datasheet, 2010, pp. 1-20.

[17] Coilcraft, “Coupled Inductors - LPR6235,” LPR6235 datasheet, 2010, pp. 1-2.

[18] A. Anders, "ECT 310 - Powering from temperature difference," white paper, 2010.

[19] Seiko, "Ultra-low voltage operation charge pump IC for step-up DCDC converter startup”, S-882Z datasheet, 2010

[20] Y. Qiu, C. Van Liempd, B.O. het Veld, P.G. Blanken, and C. Van Hoof, " $5 \mu W$-to-10mW input power range inductive boost converter for indoor photovoltaic energy harvesting with integrated maximum power point tracking algorithm", IEEE International Solid-State Circuits Conference, 2011, pp. 118-120.

[21] J. Middaugh, S. Cheng, W. Liu, and R. Wagner, "How to Make Cathodes with a Diffusion Layer for Single-Chamber Microbial Fuel Cells," 2006. Available: http://www.engr.psu.edu/ce/enve/logan /bioenergy/pdf/Cathode_093008.pdf. [Accessed June 23, 2011].

[22] B.E. Logan, S. Cheng, V. Watson, and G. Estadt, "Graphite Fiber Brush Anodes for Increased Power Production in Air-Cathode Microbial Fuel Cells," Environmental Science \& Technology, vol. 41, May. 2007, pp. 3341-3346. 